\title{
基 \\ Ocorrência de anticorpos anti-BVDV e BoHV-1 em búfalos (Bubalus bubalis) no estado do Rio Grande do Norte, Brasil
}

\author{
[Occurrence of anti-BVDV and BoHV-1 antibodies in buffalo (Bubalus bubalis) in the state of Rio \\ Grande do Norte, Brazil]
}

\section{"Artigo Científico/Scientific Article"}

\author{
Adriana Soares Leite ${ }^{1 *}$, Cid Aristóteles de Siqueira Alencar ${ }^{1}$, José Wilton Pinheiro Junior ${ }^{2}$, \\ Leucio Camara Alves ${ }^{2}$
}

\begin{abstract}
${ }^{1}$ Laboratório Federal de Defesa Agropecuária em Recife (LFDA-PE), Coordenação Geral de Laboratórios Agropecuários (CGAL), Departamento de Serviços Técnicos (DTEC), Ministério da Agricultura, Pecuária e Abastecimento (MAPA), Recife-PE, Brasil.

${ }^{2}$ Departamento de Medicina Veterinária, Universidade Federal Rural de Pernambuco (UFRPE), Recife-PE, Brasil.

*Autor para correspondência/Corresponding author: E-mail: adriana.leite@agricultura.gov.br
\end{abstract}

\section{Resumo}

Objetivou-se com este estudo determinar a ocorrência de anticorpos anti-BVDV e anti-BoHV-1 em búfalos no estado do Rio Grande do Norte. Foram analisadas 241 amostras séricas de oito machos e 233 fêmeas em idade reprodutiva por meio da técnica de vírus neutralização. Das amostras analisadas observou-se uma ocorrência de 76,7\% de anticorpos anti-BVDV e 49,8\% de anticorpos anti-BoHV-1. Entre as fêmeas positivas para ambos os agentes, havia animais com histórico de abortamento, destacando-se a associação da manifestação desse sinal clínico com a ocorrência de animais soropositivos. Foi evidenciada também a presença de machos positivos, o que contribui para a manutenção dos agentes no rebanho. Conclui-se que a elevada ocorrência de anticorpos anti-BVDV e anti-BoHV-1, podem ocasionar problemas reprodutivos na população bubalina estudada e que medidas de controle devem ser adotadas com o intuito de reduzir as perdas econômicas.

Palavras-chave: bubalinos; diarreia viral bovina; herpesvírus bovino; sorologia; doenças reprodutivas.

\begin{abstract}
The purpose of this study was to determine the occurrence of anti-BVDV and anti-BoHV-1 antibodies in buffaloes in the state of Rio Grande do Norte. Serum samples from 241 animals were analyzed: eight males and 233 females of reproductive age, using the virus neutralization technique. In total, 76.7\% of buffaloes had anti-BVDV antibodies, and 49.8\% had anti-BoHV-1 antibodies. Among females positive for both agents, there were animals with a history of abortions, demonstrating the association of this clinical sign and the occurrence of seropositive animals. The presence of positive males was also observed, which contributes to the maintenance of the agents in the herd. It is concluded that the high occurrence of anti-BVDV and antiBoHV-1 antibodies can lead to reproductive problems in the studied buffalo population, and that control measures should be adopted in order to minimize economic losses.
\end{abstract}

Keywords: buffaloes; bovine viral diarrhea; bovine herpesvirus, serology, reproductive diseases.

\section{Introdução}

A bubalinocultura é uma atividade em expansão na região Nordeste, com um rebanho estimado em 135 mil cabeças, frente a 1,30 milhão de bubalinos no Brasil, desenvolvendo-se no país como uma alternativa rentável e saudável em detrimento da sua fácil adaptabilidade ao ambiente e a expansão do mercado consumidor de produtos de origem bubalina (BRASIL, 2016).

Nos últimos anos, com a expansão da bubalinocultura no Brasil, o interesse pelo status sanitário dessa espécie vem aumentando, devido a 
sua inserção na cadeia do agronegócio. Neste sentido o conhecimento sobre a ocorrência de doenças infecciosas e seus impactos econômicos se faz necessário, somando-se ainda o fato de que bubalinos em algumas localidades são criados de forma consorciada com outras espécies, o que pode favorecer a transmissão de agentes interespécies (Fernandes et al., 2016).

De todos os patógenos, os vírus são os mais insidiosos e perigosos para o estágio inicial de desenvolvimento embrionário (Vanroose et al., 2000). Dentre as principais infecções virais associadas às perdas reprodutivas destacam-se 0 herpesvírus bovino tipo 1 (BoHV-1) e o vírus da diarreia viral bovina (BVDV) (Kirkbride, 1992; Antoniassi et al., 2007; Del Fava et al., 2007).

O BVDV (família Flaviviridae) é descrito como importante patógeno mundial em bovinos por levar a perdas significativas à bovinocultura de corte e leite. O mesmo possui dois biotipos: citopático e não citopático, de acordo com o efeito da replicação em cultivo celular. Fatores-chave na epidemiologia da infecção pelo BVDV são os animais persistentemente infectados (PI): bezerros imunotolerantes em decorrência de infecção fetal no primeiro trimestre de gestação com isolados não citopáticos. Os animais PI geralmente são soronegativos e clinicamente normais, excretando o vírus continuamente em grandes quantidades (Flores et al., 2005; Junqueira et al, 2006; Silva et al., 2011).

O BoHV-1 tem distribuição ampla, estando presente em quase todos os países de bovinocultura expressiva. Provoca alterações nos sistemas respiratório e reprodutivo de bovinos, e tem a característica de ficar latente no organismo hospedeiro (família Herpesviridae), podendo ressurgir em episódios de estresse que desencadeiem sua manifestação clínica. Embora a infecção latente tenha sido evidenciada em búfalos no Brasil por Oliveira et al. (2015), pouco se sabe sobre as enfermidades produzidas pelos BoHV-1 e BVDV em búfalos (Camargo et al., 2016).

No Brasil, alguns estudos relataram a ocorrência da infecção em búfalos pelo BVDV (Pituco et al., 1997), e pelo BoHV-1 responsável pela IBR (Cortez et al., 2001; Fujii et al., 2001), incluindo a detecção concomitante de anticorpos contra BVDV e BoHV-1 em búfalos nos estados da Paraíba, (Fernandes et al., 2016), Pernambuco (Soares et al., 2017) e Pará (Viana et al., 2016). Devido ao impacto econômico que essas infecções podem ocasionar na bubalinocultura, e à escassez de estudos sobre a ocorrência de tais enfermidades em búfalos no Nordeste brasileiro, objetivou-se com este estudo determinar a ocorrência da infecção pelos vírus da diarreia viral bovina (BVD) e da rinotraqueíte infecciosa bovina (IBR) em búfalos procedentes de um plantel no Rio Grande do Norte, Brasil.

\section{Material e Métodos}

A amostragem foi realizada por conveniência em um rebanho composto por 241 bubalinos, sendo oito machos e 233 fêmeas em idade reprodutiva (três a 16 anos), das raças Murrah e Jafarabadi. O rebanho era criado a pasto com a finalidade leiteira, sendo a ordenha realizada mecanicamente. Os animais não foram submetidos a programas de vacinação contra BVD e IBR.

O estudo foi realizado em uma propriedade localizada no estado do Rio Grande do Norte. Foram colhidos dados referentes ao manejo produtivo, sanitário e reprodutivo, como tipo de exploração, prática de quarentena, nascimento de crias fracas, queda na produção, histórico de ocorrência de animais com distúrbios reprodutivos, tais como: retenção de placenta, repetição de cio e aborto.

As amostras séricas foram obtidas mediante punção da veia lateral da cauda dos animais, utilizando-se de agulhas descartáveis e tubos de ensaio esterilizados, com capacidade para $10 \mathrm{~mL}$. $\mathrm{O}$ sangue colhido foi mantido em temperatura ambiente até a retração do coágulo sanguíneo e, em seguida, transportadas ao laboratório sob refrigeração. Após centrifugação a $900 \mathrm{~g}$ por 15 minutos, os soros obtidos foram transferidos para microtubos plásticos de polipropileno devidamente identificados e mantidos a $-20^{\circ} \mathrm{C}$ até a realização das provas sorológicas para a detecção de anticorpos anti-BVDV e BoHV-1.

Após inativação dos soros em banho-maria a $56^{\circ} \mathrm{C}$ durante 30 minutos, os soros foram diluídos em meio essencial mínimo (MEM) na proporção de 1:5 (BVD) e soro puro (IBR), em quadruplicata, com $50 \mu \mathrm{L}$ da amostra por orifício. As cepas virais empregadas foram: IBRV Colorado, proveniente da Agência de Laboratórios Veterinários (Veterinary Laboratories Agency VLA) do Departamento de Meio Ambiente, Alimentos e Assuntos Rurais do governo do Reino Unido - atualmente denominada Agência de Saúde Animal e Vegetal (Animal Plant and Heath 
Agency - APHA); e BVDV - NADL, proveniente do Centro Panamericano de Febre Aftosa (Panaftosa), e empregadas $100 \mathrm{TCID}_{50}$ para cultivo celular.

A mescla soro/vírus foi colocada em estufa com atmosfera de $5 \%$ de $\mathrm{CO}_{2}$ a $37^{\circ} \mathrm{C}$ durante uma hora, após a qual foi acrescentada suspensão de células de linhagem contínua de rim de bovino Madin-Darby Bovine Kidney (MDBK), com concentração de 250.000 células $/ \mathrm{mL}$. As microplacas foram incubadas por cinco dias e realizadas leituras diárias para observação de efeito citopático.

A prova foi validada observando-se $\mathrm{o}$ comportamento esperado dos controles positivo, negativo, de células, de toxicidade dos soros em estudo e o de retro titulação para o número de doses letais efetivamente utilizado na prova mantido entre 30 e 300 TCID $_{50}$. mostras foram consideradas como positivas quando apresentaram neutralização completa na diluição 1:10 (BVD) e 1:2 (IBR).

\section{Resultados e Discussão}

A ocorrência de anticorpos anti-BVDV na população bubalina estudada foi 76,7\% (185/241). Das 233 fêmeas, $181(77,68 \%)$ apresentaram anticorpos contra a enfermidade; e dos oito machos, quatro $(50,00 \%)$ foram positivos (Tabela 1). A alta ocorrência de anticorpos pode indicar que a infecção neste rebanho ocorreu de forma subclínica, uma vez que foi relatado no histórico do rebanho que os animais não apresentavam sinais clínicos característicos da infecção.
Contudo, vale a pena ressaltar a ocorrência de abortamento em 11,0\% (20/181) das fêmeas que foram positivas ao exame sorológico, sugerindo a associação da ocorrência de anticorpos no rebanho com a manifestação deste sinal (abortamento).

$\mathrm{Na}$ pesquisa de anticorpos anti-BoHV-1, observou-se uma ocorrência de 49,7\% (120/241) de animais positivos: dentre as 233 fêmeas, 116 $(49,79 \%)$ apresentaram anticorpos, e quatro $(50,00 \%)$ dentre os oito machos testados (Tabela 2). Ressalta-se que a população bubalina estudada é constituída por animais em idade reprodutiva, contribuindo para a ocorrência encontrada, visto que a infecção pelo vírus da IBR aumenta com o avanço da idade (Aruna e Babu, 1992), o que pode ser estendido para os animais positivos para BVD.

Das 116 fêmeas positivas para IBR, 14 apresentavam histórico de abortamento, correspondendo a $12 \%$ das fêmeas, frequência similar quando comparada a 13 fêmeas positivas para anticorpos anti-BVDV com o mesmo histórico - sugerindo a associação desses anticorpos com a ocorrência de abortos. Destacase que foi observada a coinfecção com o BVDV em 13 das 14 fêmeas citadas que se apresentaram reagentes contra o BoHV-1. Segundo Soares et al. (2017), que observaram coinfecção destas duas enfermidades em búfalos no estado de Pernambuco, esta pode estar associada à habilidade de o BVDV de causar imunossupressão, o que facilitaria a manutenção do BoHV-1 no rebanho.

Tabela 1. Infecção pela diarreia viral bovina (BVD) em búfalos no estado do Rio Grande do Norte, Brasil.

\begin{tabular}{cccc}
\hline \multirow{2}{*}{ Animais } & \multicolumn{3}{c}{ Vírus neutralização - BVD } \\
\cline { 2 - 4 } & Positivos/Total & Negativos/Total & Total \\
\hline Fêmeas & $181 / 233(77,68 \%)$ & $52 / 233(22,32 \%)$ & 08 \\
Machos & $04 / 08(50,00 \%)$ & $04 / 08(50,00 \%)$ & 241 \\
Total & $185 / 241(76,76 \%)$ & $56 / 241(23,23 \%)$ & 08 \\
\hline
\end{tabular}

Tabela 2. Infecção pela rinotraqueíte infecciosa bovina (IBR) em búfalos no estado do Rio Grande do Norte, Brasil.

\begin{tabular}{cccc}
\hline \multirow{2}{*}{ Animais } & \multicolumn{3}{c}{ Vírus neutralização - IBR } \\
\cline { 2 - 4 } & Positivos/Total & Negativos/Total & Total \\
\hline Fêmeas & $116 / 233(49,79 \%)$ & $117 / 233(50,21 \%)$ & 233 \\
Machos & $04 / 08(50,00 \%)$ & $04 / 08(50,00 \%)$ & 08 \\
Total & $120 / 241(49,79 \%)$ & $121 / 241(50,21 \%)$ & 241 \\
\hline
\end{tabular}

Neste estudo foi observada positividade para BVDV e BoHV-1 em quatro machos. O sexo dos animais pode constituir fator de risco para infecção pelo BVDV e BoHV-1, uma vez que o sêmen contaminado representa uma das principais vias de transmissão do agente (Rocha et al., 
1999). Porém, de menor relevância quando comparado à presença no rebanho de animais persistentemente infectados (PI) com o BVDV não citopático (Bolin e Grooms, 2004).

As condições de manejo dos bubalinos estudados podem favorecer a ocorrência das infecções pelos vírus da BVD e IBR, uma vez que não foi constatada a prática de segregação dos animais pelo status sorológico. Além disso, constatou-se que não existe um procedimento estabelecido de realização de exames ao introduzir animais procedentes de outros rebanhos. A movimentação irrestrita de animais e a permanência destes sob as mesmas condições de manejo afeta a prevalência encontrada nos animais estudados, corroborando com o estudo de Ahmed et al. (2015).

Um fator importante no tocante a manutenção e transmissão do BoHV-1 em rebanhos positivos é que este vírus induz infecção latente nos animais acometidos, portanto a soropositividade representa a presença do animal portador e potencial disseminador do vírus no rebanho, por toda vida (Bezerra et al., 2012).

Animais submetidos a estresse como infecção intercorrente podem apresentar imunodepressão e reativar a replicação viral do BoHV-1, e consequentemente ocorrerá reexcreção do vírus no meio ambiente (Engels e Ackermann 1996; Rocha et al., 1999; Raaperi et al., 2014). A reexcreção pode ocorrer sem recrudescência clínica, conforme citado por Medeiros et al. (2019), ao estudar a infecção latente pelo BoHV-1 em búfalos no estado do Rio Grande do Sul.

Levando-se em conta $o$ fato de tais enfermidades apresentarem sinais e sintomas não específicos ou mesmo latência, a baixa demanda pelo diagnóstico laboratorial para que este subsidie práticas de manejo, pode prejudicar a produtividade dos rebanhos estudados.

\section{Conclusão}

A elevada ocorrência de anticorpos antiBVDV e anti-BoHV-1 pode ocasionar problemas reprodutivos na população bubalina estudada. Destaca-se a importância de investigar a ocorrência dos persistentemente infectados para BVDV não citopático como fonte de infecção para os susceptíveis.

\section{Conflito de Interesse}

Os autores declaram não existir conflito de interesse.

\section{Referências}

Ahmed, W.A.; Ameer, A.H.A.; Luma, A.A.R. Preliminary investigation of IBR in bufflaoe (Bubalus bubalis) cattle (cross bred) in baghdad/Iraq. Journal of Pharmacy and Biological Sciences, 10(5): 75-78, 2015.

Antoniassi, N.A.B.; Santos, A.S.; Oliveira, E.C.; Pescador, C.A.; Driemeier, D. Diagnóstico das causas infecciosas de aborto em bovinos. Biológico, 69(2): 69-72, 2007.

Aruna, D.; Babu, T.S. Prevalence of infectious bovine rhinotracheitis (IBR) virus antibodies in buffaloes of Andhra Pradesh. Indian Journal of Animal Science, 62: 540-541, 1992.

Bezerra, D.C.; Chaves, N.P.; Sousa, V.E.; Santos, H.P.; Pereira, H.M. Fatores de risco associados à infecção pelo herpesvírus bovino tipo $1 \mathrm{em}$ rebanhos bovinos leiteiros na região Amazônica Maranhense. Arquivos do Instituto Biológico, 79(1): 107-111, 2012.

Bolin, S.R.; Grooms, D.L. Origination and consequences of bovine viral diarrhea virus diversity. Veterinary Clinics of North America: Food Animal Practice, 20: 51-68, 2004.

BRASIL. Ministério da Agricultura, Pecuária e Abastecimento. Bovinos e bubalinos. Disponível em: $<$ http://www.agricultura.gov.br/animal/especie s/bovinos-e-bubalinos>. Acesso em: 04 abr. 2016.

Camargo, D.S.; Matos, J.C.S.; Gonçalves, A.A.B.; Rodrigues, E.D.L.; Silva, S.P.; Casseb, L.M.N.; Langoni, H.; Negrão, A.M.G.; Casseb, A.R. Prevalência de anticorpos para o vírus da diarreia viral bovina, herpesvírus bovino tipo 1 e vírus da leucose enzoótica bovina em búfalos de água da Ilha de Marajó. Veterinária e Zootecnia, 23(4): 631-636, 2016.

Cortez, A.; Heinemann, M.B.; Alfieri, A.A.; Médici, K.C.; Alfieri, A.F.; Oliveira, D.B.; Meyer, A.D.; Soares, R,M.; Sakamoto, S.M.; Amaral, R. Baruselli, P.S.; Fujii, T.; Richtzenhain, L.J. Comparação das técnicas de ELISA indireto e de soroneutralização na detecção de anticorpos contra o BHV-1 em amostras de soro bubalino (Bubalus bubalis). Brazilian Journal of Veterinary Research and Animal Science, 38(3): 146-148, 2001. 
Del Fava, C.; Pituco, E.M.; Genovez, M.E. Diagnóstico diferencial de doenças da reprodução em Bovinos: experiência do Instituto Biológico. Biológico, 69(2): 73-79, 2007.

Engels, M; Ackermann, M. Pathogenesis of ruminat herpesvirus infections. Veterinary Microbiology, 53: 3-15, 1996.

Fernandes, L.G.; Pimenta, C.L.R.M.; Pituco, E.M.; Brasil, A.W.L.; Azevedo, S.S. Risk factors associated with BoHV-1 and BVD seropositivity in buffaloes (Bubalus bubalis) no Estado da Paraíba, Nordeste do Brasil. Semina: Ciências Agrárias, 37(4): 19291936, 2016.

Flores, E. F.; Weiblen, R.; Flores, F.S.; Vogel, P. M.; Roehe, A.; Alfieri, A; Pituco, E.M. A infecção pelo vírus da Diarréia Viral Bovina (BVDV) no Brasil - histórico, situação atual e perspectivas. Pesquisa Veterinária Brasileira, 25(3): 125-134, 2005.

Fujii, T.U.; Kasai, N.; Vasconcellos, S.A.; Richtzenhain, L.J.; Cortez, A.; Souza, S.L.P.; Baruselli, P.S.; Nishi, S.M.; Ferreira, F.; Gennari, S.M. Anticorpos anti-Neospora caninum, e contra outros agentes de abortamentos em búfalas da região do Vale do Ribeira, São Paulo, Brasil. Arquivos do Instituto Biológico, 68(2): 5-9, 2001.

Junqueira, J.R.C.; Alfieri, A.A. Falhas da reprodução na pecuária bovina de corte com ênfase para causas infecciosas. Semina: Ciências Agrárias, 27(2): 289-298, 2006.

Kirkbride, C.A. Viral agents and associated lesions detected in a 10-year study of bovine abortions and stillbirths. Journal of Veterinary Diagnostic Investigation, 4: 374-379, 1992.

Medeiros, D.M.; Campos, F.S.; Lima, M.; Hubner, S.O.; Vargas, G.D.A; Fischer, G. Infecção latente pelo herpesvírus bovino tipo $1 \mathrm{em}$ búfalos (Bubalus bubalis) no Rio Grande do Sul. Arquivo Brasileiro de Medicina Veterinária e Zootecnia, 71(4): 1236-1242, 2019.

OIE. Organização Mundial de Saúde Animal. Infectious bovine rhinotracheitis/infectious pustular vulvovaginitis. Manual of diagnostic tests and vaccines for terrestrial animals. $7^{\text {th }}$ ed. Paris: OIE, 2012. p.1-17.

Oliveira, R.A.M; Lorenzetti, E.; Alfieri, A.A.; Lisbôa, J.A.N. Prevalência das infecções latentes por BoHV-1 e BoHV-5 em bovinos de corte no Estado do Paraná. Arquivo Brasileiro de Medicina Veterinária e Zootecnia, 67(5): 1217-1225, 2015.

Pituco, E.M.; Del Fava, C.; Okuda, L.H. Prevalência da infecção pelo vírus da diarréia bovina a vírus (BVD) em búfalos (Bubalus bubalis) no Vale do Ribeira, SP, Brasil. Arquivos do Instituto Biológico, 64(1): 2328, 1997.

Raaperi, K.; Orro, T.; Viltrop, A. Epidemiology and control of bovine herpesvirus 1 infection in Europe. The Veterinary Journal, 201: 249256, 2014.

Rocha, M.A.; Gouveia, A.M.G.; Leite, R.C. Herpesvírus bovino tipo 1 no sêmen. Ciência Rural, 29(2): 373-380, 1999.

Silva, M.V.M.; Nogueira, J.L.; Junior, V.P.; Fernandes, R.A. Diarréia viral bovina: patogenia e diagnósticos - revisão de literatura. Revista Científica Eletrônica de Medicina Veterinária, IX(16): 1-9, 2011.

Soares, B.F.L.; Pajeú e Silva, B.; Borges, J.M.; Oliveira, J.M.B.; Macêdo, A.A.; Aragão, B.B.; Nascimento, S.A.; Pinheiro Júnior, J.W. Occurrence of bovine viral diarrhea (BVDV) and bovine infectious rhinotracheitis (IBR) virus infections in buffaloes in Pernambuco state. Acta Scientiae Veterinariae, 45: 1459, 2017.

Vanroose, G.; Kruif, A.; Van Soom, A. Embryonic mortality and embryo-pathogen interactions. Animal Reproduction Science, 60-61: 131$143,2000$.

Viana, R.B.; Del Fava, C.; Monteiro, B.M.; Moura, A.C.B.; Albuquerque, R.S.; Cardoso, E.C.; Araújo, C.V.; Pituco, E.M. Ocorrência do vírus da leucose enzoótica dos bovinos (BLV) e de anticorpos contra herpesvírus bovino tipo-1 (BoHV-1) e vírus da diarreia viral bovina (DVDV) em búfalos no Estado do Pará. Acta Scientiae Veterinariae, 44: 1357, 2016. 